\title{
Hand-foot syndrome associated with use of sorafenib in a patient with papillary thyroid cancer: a case report
}

\author{
Carlos Velandia-Carrillo ${ }^{1 *}$, Edwin Wandurraga-Sánchez ${ }^{2,3}$ and Diego Gómez-Abreo ${ }^{4,5}$
}

\begin{abstract}
Background: Hand-foot syndrome (HFS), also known as palmar-plantar Erythrodysesthesia (PPE), acral erythema or Burgdorf reaction, is a dermatologic toxic reaction to certain chemotherapies, including sorafenib. A high incidence of adverse events is already described in dermatological clinical trials of this drug, but its use in medical practice, common in the patient with metastatic thyroid carcinoma has not yet been reported. Sorafenib (BAY 43-9006) is an orally administered multi-level kinase inhibitor, approved for treatment of solid tumors such as renal cell carcinoma, hepatocellular carcinoma and recently for metastatic thyroid carcinoma.
\end{abstract}

Case presentation: We report a case of a 29 year old Latin woman diagnosed with papillary thyroid carcinoma, who was initially given a total thyroidectomy, central and bilateral neck lymph node removal followed by a radioiodine therapy. Subsequent evaluation indicated locoregional progressive disease and metastatic involvement in both lungs. Following this, the patient was prescribed $200 \mathrm{mg}$ of sorafenib administered every 12 hours, but after four days, she presented with a skin reaction compatible with hand-foot syndrome. After discontinuation of the therapy, this reaction ceased.

Conclusion: Sorafenib as a new therapeutic option for patients with radioactive iodine (RAl)-resistant metastatic differentiated thyroid cancer, it is important that clinicians are fully aware of the potential adverse effects. All patients on Sorafenib therapy should be educated to recognize the first symptoms to obtaining the maximal benefit from this anti-neoplastic rescue therapy.

Keywords: Hand-foot syndrome, Palmo-plantar Erythrodysesthesia, Sorafenib, Thyroid Cancer, Tyrosin kinase inhibitor, Targeted therapies

\section{Background}

Thyroid cancer is the most common endocrine neoplasia globally, with approximately 8.7 cases per 100,000 populations [1]. Although it usually has a favorable prognosis, an incidence of 0.5 deaths per 100,000 populations is estimated [2]. Surgery is considered the first-line therapy, while radioactive iodine has played an important role over the years in postsurgical remnant ablation and therapy of metastatic distant disease [3,4]. However, the therapeutic options for patients with advanced radioactive iodine (RAI)-refractory desease are limited. Doxorubicin had been accepted by

\footnotetext{
* Correspondence: carlos.velandia@gmail.com

'Universidad Autónoma de Bucaramanga-UNAB, Tower B, Eighth Floor, Office 806 Street 155 A 23-09, Urbanización El Bosque, Floridablanca, Santander, Colombia

Full list of author information is available at the end of the article
}

most countries as the only systemic treatment, which has traditionally been a limited option due to the rarity of complete and partial responses and because of its significant toxicity [5]. Recently the US department of food and drug administration (FDA) approved the use of Sorafenib (BAY43 -9006) for the treatment of differentiated thyroid cancer metastases unresponsive to radioiodine treatment [6]. This drug had previously been approved for the treatment of hepatocellular carcinoma [7] and advanced renal carcinoma [8].

Sorafenib is a molecule capable of multi - level kinase inhibition, with particular activity against VEGFR and RAF (the RAF/MEK/ERK pathway), a major pathway involved in the proliferation of tumor cells [9], opposing c -RAF, B -Raf, c- KIT, FLT3, Platelet-derived growth factor receptor (PDGFR) $\alpha$ and $\beta$, vascular endothelial 
growth factor receptor (VEGFR) 1, 2, and 3, and various other kinases [10], giving this medicine both pro - apoptotic properties and anti-angiogenic effects. This is of special interest in the treatment of thyroid carcinomas [9], based on the understanding that mutations in the protein kinase BRAF, play a key role in carcinogenesis in up to $45 \%$ of cases of papillary thyroid cancer (PTC). Ras mutations and rearrangements in the RET (RET/ PTC) gene are also involved in $10 \%$ and $5-30 \%$ of cases, respectively [11]. Adverse events with the use of Sorafenib for treatment of renal carcinoma [12] occur in up to $73 \%$ of patients as case of fatigue, rash/desquamation (up to $66 \%$ of patients), hand-foot skin reaction (up to $62 \%$ of patients) and diarrhea (up to $58 \%$ of patients). Similar prevalence is observed in treatment of hepatocellular carcinoma [13].

The safety and efficacy of Sorafenib in treating thyroid cancer were established in the Phase III DECISION study (Sorafenib in Locally Advanced or Metastatic RAI- Refractory Patients with Thyroid Cancer) in patients with locally recurrent or progressive metastatic differentiated thyroid cancer who had not responded to treatment with radioactive iodine [14]. This study randomized 417 patients to $400 \mathrm{mg}$ of orally administered sorafenib taken every 12 hours, versus placebo. A partial response was observed in $12.2 \%$ of the patients receiving Sorafenib compared to $0.5 \%$ in the placebo group. Those receiving sorafenib also had a 5 month greater disease-free survival rate compared to the placebo group (10.8 vs. 5.8 months, HR $0.587,95 \%$ CI $[0.454,0.758], \mathrm{p}<0.0001) .18 \%$ of patients discontinued medication due to adverse events in the Sorafenib group. Hand-foot syndrome which presented in $76.3 \%$ of patients and it was severe (grade 3 ) in $20.3 \%$. Other symptoms reported were diarrhea in $68.6 \%$, alopecia in $67.1 \%$, rash/desquamation in $50.2 \%$, fatigue in $49.8 \%$, weight loss in $46.9 \%$ and hypertension in $40.6 \%$ [15]. In the present report we describe the case of a patient presenting with HFS after four days of $400 \mathrm{mg} /$ day of oral Sorafenib. HFS toxicity is measured and recorded according to The National Cancer Institute (NCI) grading systems for dermatologic toxicities (NCI Common Terminology Criteria [CTC] v2.0 and CTC for Adverse Events [CTCAE] v3.0 (see Table 1 [16]). However, these side effects required permanent discontinuation of the treatment in only $18.8 \%$ of patients $[14,15,17]$.

Consensus panel recommendations for different degrees of toxicity management follow:
For grade 1 HFS the use of moisturizing creams is recommended and patients should avoid hot water. Cotton gloves and socks can be worn at night to prevent further injury and to help retain moisture, no dose modifications of the Sorafenib are recommended in addition to continuation of prophylactic measures and a follow-up in the clinic. Keratolytics, such as urea $20 \%-40 \%$, or salicylic acid 6\% may be indicated.

For grade 2 treatment should continue as for grade 1 toxicity with the following additions. Consider applying Clobetasol $0.05 \%$ to erythematous areas twice daily, using topical analgesics such as Lidocaine $2 \%$ and assess kidney function before prescribing any systemic pain medications (e.g., nonsteroidal anti-inflammatory drugs, codeine, pregabalin). If necessary, consider a dose reduction to $50 \%$ of the full dose for a minimum of 7 days, up to 28 days, until the HFS reaches grade 1.

For grade 3 the recommendation is provide treatment as indicated for grades 1 and 2 and to include the following: Discontinue the Sorafenib for a minimum of 7 days until the HFS reaches grade 1 or 0 , and then resume treatment at $50 \%$ of the full dose [18].

\section{Case presentation}

A 29 year old Latina female with a history of papillary thyroid carcinoma was initially treated with a total thyroidectomy, central and bilateral neck lymph node removal and subsequently with radioiodine therapy. Following this, evaluation indicated locoregional progressive disease and micrometastatic involvement in both lungs. Therapy was then initiated with $200 \mathrm{mg}$ of oral sorafenib every 12 hours. However, after 4 days the patient presented with cutaneous lesions in the sole of the foot and in the first finger of the left hand which was associated with a burning pain in soles and palms and an intolerance to contact with hot surfaces. She also had significant ambulatory limitations and patchy lesions were evident in several areas of the foot and yellow blisters on the lateral aspect of the foot, metatarsal region and on the proximal phalanx of the first finger of the left hand (Figure 1). Given these clinical findings the dermatological reaction was classified as Grade 3 and the Sorafenib treatment was discontinued. We then initiated treatment with a topical steroid, oral antihistamines and local management with ice packs around the lesions and observed the beginning of recovery seven days after the patient discontinued the drug therapy (Figure 2).

Table 1 Severity of hand-foot syndrome

\begin{tabular}{ll}
\hline Grade & Hand-foot syndrome \\
\hline 1 & Minimal skin changes or dermatitis (e.g., erythema, edema, or hyperkeratosis) without pain. \\
2 & Skin changes (e.g., peeling, blisters, bleeding, edema, or hyperkeratosis) with pain; limiting instrumental activities of daily living. \\
3 & Severe skin changes (e.g., peeling, blisters, bleeding, edema, or hyperkeratosis) with pain; limiting self care activities of daily living. \\
\hline
\end{tabular}




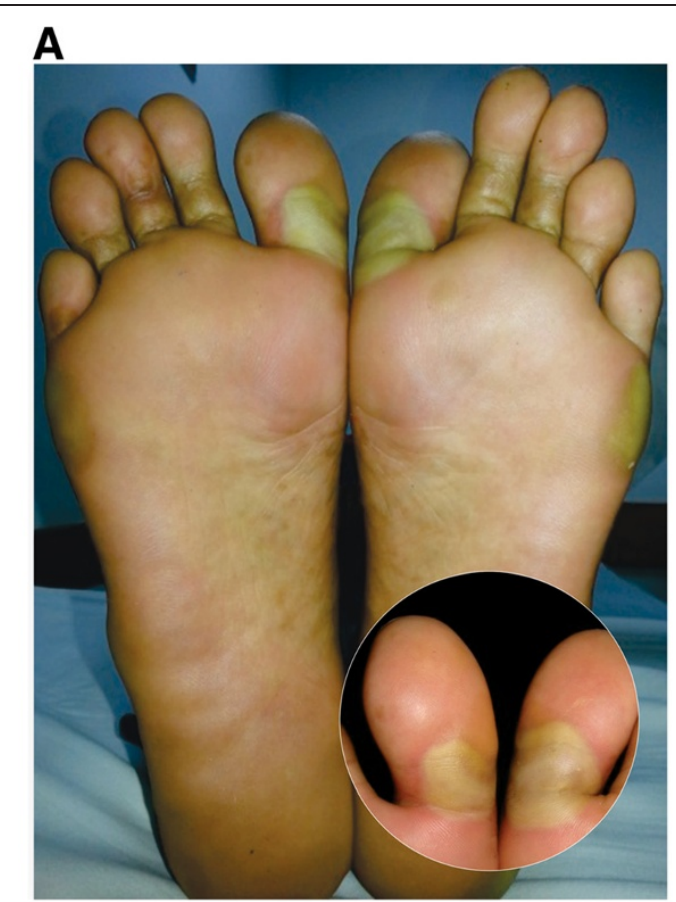

\section{B}

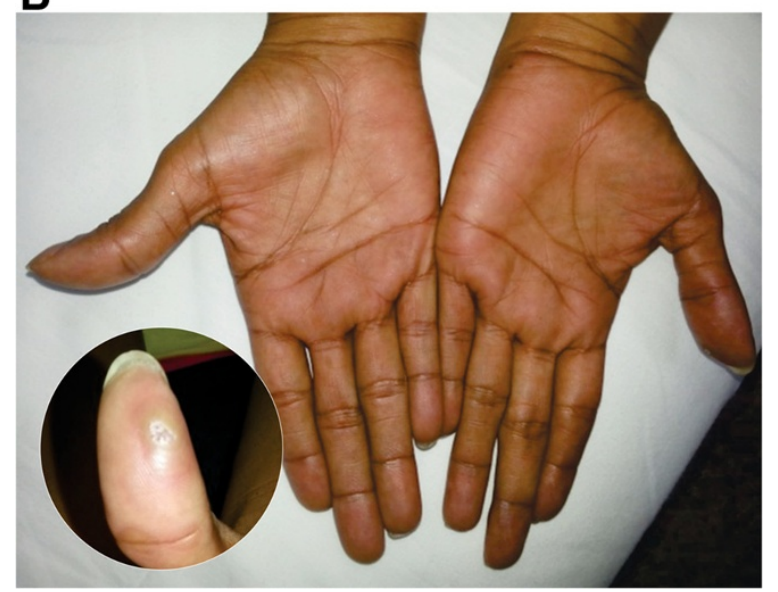

Figure 1 Hand-foot syndrome on the soles (A) and palms (B) (4 days after onset of sorafenib).

\section{Conclusions}

Sorafenib (BAY 43-9006) is the first approved systemic therapy in the management of radioactive iodine (RAI)-resistant metastatic differentiated thyroid cancer. The use of Sorafenib, is however associated with a relatively high incidence of adverse events already described in dermatological clinical trials of this drug, but its use in medical practice, common in the patient with metastatic thyroid carcinoma has not yet been reported and this is one of the first post marketing reports.

Hand-foot syndrome (HFS) is a relatively frequent dermatologic toxic reaction to certain chemotherapies for cancer. Its pathogenesis is not well defined, it is usually mild, but can progress to a severe condition that limits

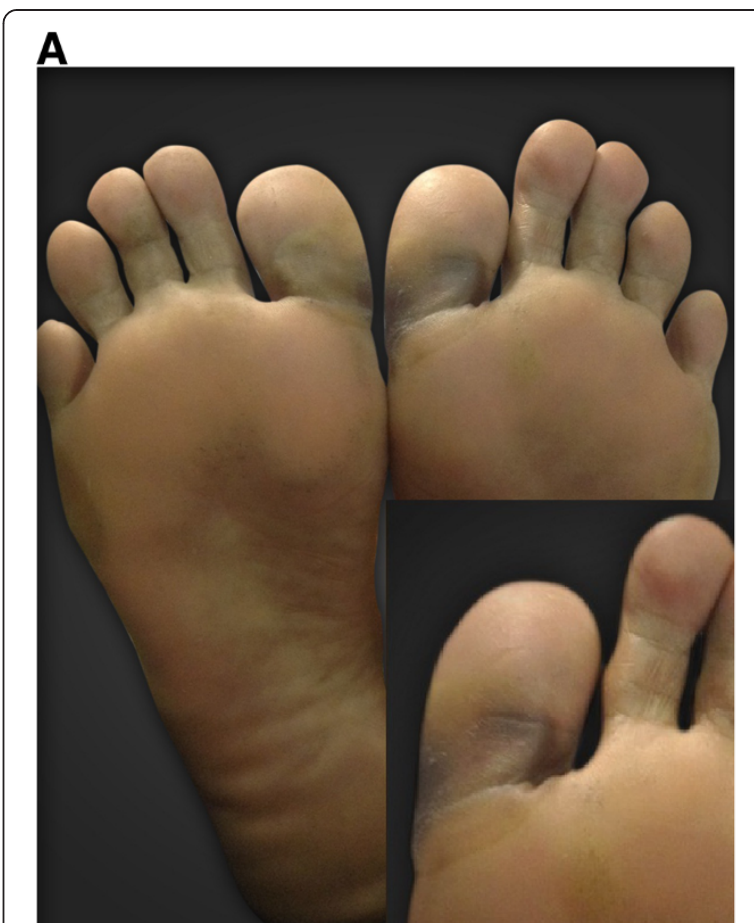

B

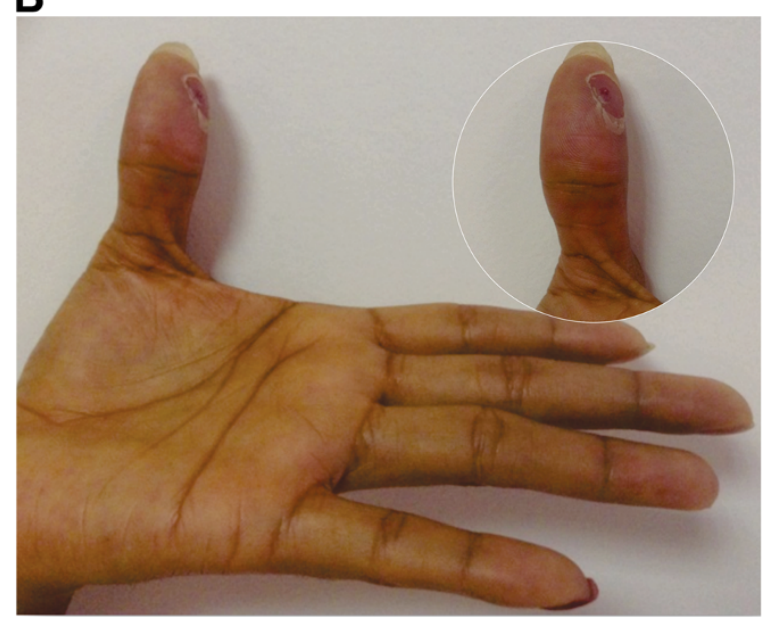

Figure 2 Hand-foot syndrome on the soles (A) and palms (B) (7 days after suspension of sorafenib and start symptomatic treatment).

function and affects quality of life. The most frequently used therapies are topical emollients, pain medications and reduction from the full dose or discontinuation of the Sorafenib therapy followed by resumption of treatment at $50 \%$ of the full dose often associated with good response rate.

Given the incidence of thyroid carcinoma, and the importance of Sorafenib as a new therapeutic option for patients with advanced radioactive iodine (RAI)-refractory desease, it is important that clinicians including endocrinologists, medical oncologists who manage these therapies are fully aware of the potential adverse effects. All patients on Sorafenib therapy should be educated to recognize the 
first symptoms, to manage initial prevention and consider dose reduction or discontinue the therapy to improve the patient's quality of life by minimizing the impact of adverse events while obtaining the maximal benefit from this anti-neoplastic rescue therapy.

\section{Consent}

Written informed consent was obtained from the patient for publication of this Case report and any accompanying images. A copy of the written consent is available for review by the Editor of this journal.

\section{Abbreviations \\ (HFS): Hand-foot syndrome; (VEGFR): Vascular endothelial growth factor receptor; (FDA): Food and Drug Administration; (PPE): Palmar-plantar Erythrodysesthesia; (PDGFR): Platelet-derived growth factor receptor; (RAl): Radioactive iodine.}

\section{Competing interests}

The authors declare that they have no political, personal, religious, ideological, academic, intellectual, commercial or any other competing interests.

\section{Authors' contributions}

CAVC carried out the: wrote the manuscript, data collection, reviewed and edited manuscript. EAWS carried out the: data collection reviewed and edited manuscript; DAGA carried out the reviewed and edited manuscript. All authors read and approved the final manuscript.

\section{Authors' information}

CAVC: Author; Internal Medicine Resident first year, Universidad Autónoma de Bucaramanga-UNAB.

EAWS: Author; Endocrinologist, Assistant Professor of Medicine, Universidad Autónoma de Bucaramanga-UNAB.

DAGA: Co-author; Medical Oncologist, Coordinator of the Department of Clinical Oncology, Cal ONCOLOGICOS, Bucaramanga, Colombia.

\section{Acknowledgements}

We thank Ruben Dario Mantilla who provided in the photography services on behalf of Fundacion Oftalmologica de Santander-FOSCAL.

\section{Author details}

'Universidad Autónoma de Bucaramanga-UNAB, Tower B, Eighth Floor, Office 806 Street 155 A 23-09, Urbanización El Bosque, Floridablanca, Santander, Colombia. ${ }^{2}$ Department of Endocrinology, Fundación Oftalmológica de Santander-FOSCAL Clinic, Universidad Autónoma de Bucaramanga-UNAB, Bucaramanga, Colombia. ${ }^{3}$ Tower B, Eighth Floor, Office 806 Street 155 A 23-09, El Bosque, Floridablanca, Santander, Colombia. ${ }^{4}$ Department of Clinical Oncology, Cal ONCOLOGICOS, Bucaramanga, Colombia. ${ }^{5}$ González Valencia Street \# 55b-07, Bucaramanga, Santander, Colombia.

Received: 20 December 2013 Accepted: 5 March 2014

Published: 19 March 2014

\section{References}

1. Jemal A, Siegel R, Xu J, Ward E: Cancer statistics, 2010. CA Cancer J Clin 2010, 60:277-300

2. Davies L, Welch HG: Increasing incidence of thyroid cancer in the United States, 1973-2002. JAMA 2006, 295:2164-2167.

3. American Thyroid Association (ATA) Guidelines Taskforce on Thyroid Nodules and Differentiated Thyroid Cancer, Cooper DS, Doherty GM, Haugen BR, Kloos RT, Lee SL, Mandel SJ, Mazzaferri EL, Mclver B, Pacini F, Schlumberger M, Sherman SI, Steward DL, Tuttle RM: Revised American Thyroid Association management guidelines for patients with thyroid nodules and differentiated thyroid cancer. Thyroid 2009, 19:1 167-1214.

4. Tuttle RM, Ball DW, Byrd D, Dilawari RA, Doherty GM, Duh QY, Ehya H, Farrar WB, Haddad RI, Kandeel F, Kloos RT, Kopp P, Lamonica DM, Loree TR, Lydiatt WM, McCaffrey JC, Olson JA Jr, Parks L, Ridge JA, Shah JP, Sherman SI, Sturgeon C, Waguespack SG, Wang TN, Wirth LJ, National
Comprehensive Cancer Network: Thyroid carcinoma. J Natl Compr Canc Netw 2010, 8:1228-1274.

5. Kim JH, Leeper RD: Treatment of locally advanced thyroid carcinoma with combination doxorubicin and radiation therapy. Cancer 1987, 60:2372-2375.

6. U.S. Food and Drug Administration: FDA approves Nexavar to treat type of thyroid cancer. Available from: [http://www.fda.gov/newsevents/ newsroom/pressannouncements/ucm376443.htm]

7. Llovet JM, Ricci S, Mazzaferro V, Hilgard P, Gane E, Blanc JF, de Oliveira AC, Santoro A, Raoul JL, Forner A, Schwartz M, Porta C, Zeuzem S, Bolondi L, Greten TF, Galle PR, Seitz JF, Borbath I, Haussinger D, Giannaris T, Shan M, Moscovici M, Voliotis D, Bruix J: Sorafenib in advanced hepatocellular carcinoma. N Engl J Med 2008, 359:378-390.

8. Escudier BSC, Eisen T: Randomized phase III trial of the Raf kinase and VEGFR inhibitor sorafenib (BAY 43-9006) in patients with advanced renal cell carcinoma (RCC). J Clin Oncol 2005, 23(165):LBA4510.

9. Wilhelm SM, Carter C, Tang L, Wilkie D, McNabola A, Rong H, Chen C, Zhang X, Vincent P, McHugh M, Cao Y, Shujath J, Gawlak S, Eveleigh D, Rowley B, Liu L, Adnane L, Lynch M, Auclair D, Taylor I, Gedrich R, Voznesensky A, Riedl B, Post LE, Bollag G, Trail PA: BAY 43-9006 exhibits broad spectrum oral antitumor activity and targets the RAF/MEK/ERK pathway and receptor tyrosine kinases involved in tumor progression and angiogenesis. Cancer Res 2004, 64:7099-7109.

10. Fabian MA, Biggs WH 3rd, Treiber DK, Atteridge CE, Azimioara MD, Benedetti MG, Carter TA, Ciceri P, Edeen PT, Floyd M, Ford JM, Galvin M, Gerlach JL, Grotzfeld RM, Herrgard S, Insko DE, Insko MA, Lai AG, Lélias JM, Mehta SA, Milanov ZV, Velasco AM, Wodicka LM, Patel HK, Zarrinkar PP, Lockhart DJ: A small molecule-kinase interaction map for clinical kinase inhibitors. Nat Biotechnol 2005, 23:329-336.

11. Capdevila J, Iglesias L, Halperin I, Segura A, Martinez-Trufero J, Vaz MA, Corral J, Obiols G, Grande E, Grau JJ, Tabernero J: Sorafenib in metastatic thyroid cancer. Endocr Relat Cancer 2012, 19:209-216.

12. Ratain MJ, Eisen T, Stadler WM, Flaherty KT, Kaye SB, Rosner GL, Gore M, Desai AA, Patnaik A, Xiong HQ, Rowinsky E, Abbruzzese JL, Xia C, Simantov R, Schwartz B, O'Dwyer PJ: Phase II placebo-controlled randomized discontinuation trial of sorafenib in patients with metastatic renal cell carcinoma. J Clin Oncol 2006, 24:2505-2512.

13. Strumberg D, Awada A, Hirte H, Clark JW, Seeber S, Piccart P, Hofstra E, Voliotis D, Christensen O, Brueckner A, Schwartz B: Pooled safety analysis of BAY 43-9006 (sorafenib) monotherapy in patients with advanced solid tumours: is rash associated with treatment outcome? Eur J Cancer 2006, 42(4):548-556.

14. Brose MS, Nutting CM, Sherman SI, Shong YK, Smit JW, Reike G, Chung J, Kalmus J, Kappeler C, Schlumberger M: Rationale and design of decision: a double-blind, randomized, placebo-controlled phase III trial evaluating the efficacy and safety of sorafenib in patients with locally advanced or metastatic radioactive iodine (RAl)-refractory, differentiated thyroid cancer. BMC Cancer 2011, 11:349.

15. Brose MS, Nutting CM, Sherman SI, Shong YK, Smit JW, Reike G, Chung J, Kalmus J, Kappeler C, Schlumberger M: Sorafenib in locally advanced or metastatic patients with radioactive iodine-refractory differentiated thyroid cancer: the phase III DECISION trial. J Clin Oncol 2013, 31 (suppl 4).

16. Trotti A, Colevas AD, Setser A, Rusch V, Jaques D, Budach V, Langer C, Murphy B, Cumberlin R, Coleman CN, Rubin P: CTCAE v3.0: development of a comprehensive grading system for the adverse effects of cancer treatment. Semin Radiat Oncol 2003, 13:176-181.

17. Brose MS: Sorafenib in locally advanced or metastatic patients with radioactive iodine-refractory differentiated thyroid cancer: the Phase 3 DECISION trial, Presented at 13th ASCO Annual Meeting Proceedings. In Chicago; 2013.

18. Lacouture ME, Wu S, Robert C, Atkins MB, Kong HH, Guitart J, Garbe C, Hauschild A, Puzanov I, Alexandrescu DT, Anderson RT, Wood L, Dutcher JP: Evolving strategies for the management of hand-foot skin reaction associated with the multitargeted kinase inhibitors sorafenib and sunitinib. Oncologist 2008, 13:1001-1011.

doi:10.1186/1472-6823-14-26

Cite this article as: Velandia-Carrillo et al:: Hand-foot syndrome associated with use of sorafenib in a patient with papillary thyroid cancer: a case report. BMC Endocrine Disorders 2014 14:26. 